Regulatory influences on innovation in the public sector: the role of regulatory regimes

Beverly Wagner

Reader in marketing

Strathclyde Business School, University of Strathclyde

199 Cathedral Street

G4 ORQ Glasgow, United Kingdom

Tel.: +44 (0)1425483246

beverly.wagner@strath.ac.uk

Nusa Fain*

Lecturer in marketing

Strathclyde Business School, University of Strathclyde

199 cathedral Street

G4 ORQ Glasgow, United Kingdom

Tel.: +44 (0)1425483093

nusa.fain@strath.ac.uk

* corresponding author

Acknowledgement: Part of this research was funded by the Water Industry Commission for Scotland. 
REGULATORY INFLUENCES ON INNOVATION IN THE PUBLIC SECTOR: THE ROLE OF REGULATORY REGIMES

Abstract

The purpose of this paper is to explore the impact of regulation on innovation within the public sector. This is done by integrating two separate frameworks, related to regulatory regimes and public sector innovation. Through a case study of the Scottish water sector a matrix integrating these frameworks has been empirically developed, illustrating a continuous improvement path for innovation in the Scottish water sector. Findings indicate that customer and shareholder accountability is manifest at the transitional interface of the regulatory regimes, facilitating movement within the different systems. Interplay with the accountabilities and adjustments to the regulatory regime are paramount for progress. Through incentives to establish partnerships, the Regulator provides conditions for new ideas to emerge with reduced risk of failure. Experimentation allows a new approach towards solving problems and enhancing innovation potential within the sector. The contribution of this paper is a framework demonstrating mechanisms required to move between government-centred, compliancebased regulation through to performance oriented regulatory regimes.

Keywords: innovation, regulatory regimes, public sector, utilities 


\section{REGULATORY INFLUENCES ON INNOVATION IN THE PUBLIC SECTOR: THE ROLE OF REGULATORY REGIMES}

\section{Introduction}

It is frequently suggested that public organizations are less innovative than private sector organizations (Walker 2014). The stereotypical view suggests that Regulatory bodies hamper innovation due to constraints by regulation (Stewart 2010) and bureaucracy (Walker 2014). This charge is particularly aimed at the public utility sector where hindsight reviews promote costminimising models that forgo investment in innovation, preferring costly conventional technologies, rather than seeking improved solutions (Lyon 1995; Sørensen and Torfing 2011; Mills and Koliba 2015; UKRN 2015). To remain competitive, public sector organizations should adapt managerial and regulatory practices to foster innovation rather than maintain the status quo (Agolla and Van Lill 2013; Bysted and Rosenberg 2015). This has been addressed to some degree in initiatives such as New Public Management, the "Big Society" and changes from government to governance, designed to alleviate tensions between innovation and bureaucracy (De Vries et al. 2016).

There is little empirical evidence of the role of regulation in innovative behaviour (Vigoda-Gadot, et al. 2005). Accordingly, this paper addresses the foregoing by a cross-disciplinary approach, merging governance, regulation principles and accountability structures with innovation management in order to consider the impact of regulation on public sector innovation.

The paper also addresses a research gap highlighted by Mills and Koliba (2015) who identified a need for in-depth analysis of accountability structures within regulatory governance networks. The key research question guiding this study is: To what extent, if any, does a regulatory framework inhibit innovation within the public sector environment? To address the research question, innovation in public sector, regulatory regimes and governance will be examined.

The contribution of this paper lies in development of a framework that explores the fit between regulatory constraints to innovation and regulatory regimes. It proposes mechanisms relevant for the public sector that maintain regulatory compliance while fostering innovation. The framework's managerial implications are illustrated in the case of the Scottish Water Sector.

\section{Context}

The incentive for this research came from the Regulatory body's desire to explore the impact of regulation on innovation within the Scottish water sector (Granger 2007). It was intended to assess whether innovation and creativity are stifled or inhibited by the regulatory framework and if so, what 
actions could be considered to support innovation. In turn, this could allow scope for regulatory incentives to act as a positive driver for innovation leading to the development of new regulatory approaches.

This topic is potentially important, as historically regulation has been seen as an inhibitor of innovation within the public sphere. At the same time, regulatory regimes have evolved in order to address the negative impacts of prescriptive rules and regulations on competitive economies (May 2007; Mills and Koliba 2013). Policy makers have started to systematically look into the mitigation of these negative influences (Blind 2012), however there is very limited research relating to how regulation can positively influence innovative performance of public sector institutions (Battisti and Stoneman 2010; Brysted and Hansen 2015; Jacquemin and Janssen 2015).

This study goes some way to address this gap first by synthesising Agolla and Van Lill's (2013) and De Vries et al. (2016) frameworks for public sector innovation to establish key dimensions that impact public sector innovation in general. Secondly, the paper incorporates regulatory regimes and accountability levels set out by May (2007) to conceptualise the impact of regulation on innovation. The managerial implications of the proposed framework are discussed through the illustrative case within the Scottish water sector.

\section{Defining innovation in the public sector}

In an extensive systematic literature review, De Vries et al (2016) note that most articles related to innovation in the public sector do not define innovation and if they do, use Rogers (2003 p12), who described innovation as "an idea, practice, or object that is perceived as new by an individual, or other unit of adoption." Generic definitions are too broad and do not address the complexity and nuances of public sector innovation.

In public organizations, one-off standalone innovations are not the norm and innovation is evolutionary rather than radical (Walker 2007). Walker (2007) defines innovation as new services offered by public organizations to satisfy external users by addressing a market need. Thus, innovations in the public services are related to new ways of managing, organising and delivering services. Stewart (2010) describes innovation as a new or significantly improved service, communication method, process or organizational method. Currie et al. 2008 (cited in ANAO report, 2009) define public sector innovation as the quest for creative, unusual or novel solutions to problems and needs, including new services, new organizational forms and process innovation.

In the UK Regulators Network's (UKRN) summary report (2015), innovation is defined as "a process of creating new methods, or adoption of alternative methods, to create improved outcomes." This 
can mean technical, process or commercial innovation and often involves a certain level of risk. Innovations are a key process in job creation, higher incomes and solving social problems (Agolla and Van Lill 2013; Walker 2014). This is where process ideas are transformed into new forms of added value for organizations, stakeholders, customers and employees. Innovation occurs in a systemic context, rather than in a linear way and consideration of all systemic aspects is needed so as to understand how innovation works (Akrich et al. 2002; Candi et al. 2013; Chiva et al. 2014).

Luke et al (2010) suggest two types of public sector innovation, namely market (price control, entry conditions) and social (protecting the welfare of society, the environment, health and regulations). Market innovation typically benefit producers, consumers and society, whereas social innovation refers to product and process innovation creating social benefits that cannot be directly captured by market sales. Agolla and Van Lill (2013, p166), synthesise the foregoing by defining innovation in the public sector as the "creation of novel ideas or knowledge and application of new knowledge to create products and services that generate value for the public sector."

Innovation may be described as incremental, radical or systemic (Stewart 2010). In the public sector, incremental innovation is when firms make relatively minor improvements to existing products or services and in so doing, meet standards for regulation compliance. Radical innovation replaces existing products and services by introducing a new service or implementing a new delivery method. Radical innovation does not alter the dynamics of the sector although it is often risky and costly. Systemic or transformational innovation is rare and is usually driven by technological changes. Of these, incremental innovation is the most attractive as it means that public sector companies remain within the bounds of regulatory rules (Walker 2007).

Although radical innovation may provide the most benefit, the associated risks and costs of failure deter public sector organizations from engaging in such efforts (Luke 2010). Sector differences in relation to bureaucracy, conflicting goals or lack of market pressure may be mediated due to the degree of autonomy, expectations, room for innovation and risk culture (Brysted and Hansen 2015). Regulations most effective in stimulating innovation, minimise the compliance burden and mitigate risk of producing unsuccessful innovation.

Stereotypical perceptions of public and private sector differences dominate (Brysted and Hansen (2015). In traditional public organizations, bureaucratic red tape and constraining regulation are deemed barriers to innovative action and there is little discussion relating to the role of enabling regulations that create opportunities for innovation and entrepreneurial behaviour (Jacquemin and Janssen 2015). In the public sector, the main stakeholder is the Government, however, despite many 
governmental reports on the relevance of innovation in the public sector, contradictory views remain on the influence of regulation in the innovation process (Stewart 2010).

\section{Factors influencing Innovation in the public sector}

Innovation is a key driver of competitiveness and economic growth, though nurturing it is a challenging task that involves multiple and constantly changing actors. Although collaboration and engagement with the environment are emphasised as determinants of successful innovation, organizations often run into information sharing, management and coordination problems (Walker 2007; Barczak et al. 2009; Sørensen and Torfing 2011). This means understanding how collaboration, coordination and external influences can be mitigated to support effective innovation performance is of great importance (Battisti et al. 2010).

Barriers associated with public sector innovation have been identified in a number of studies. For example Sørensen and Torfing (2011) cite rules, bureaucratic silos, red tape, inertia and performance measures that focus on input and outputs as preventing innovation. Risk averse cultures (Borins 2001; Brysted and Hansen 2015) and political intervention are also major inhibiting factors (Koch and Hauknes 2005; Koch et al. 2006; McMillan and Carlisle 2007; Hughes et al. 2011). These influences on innovation within the public sector can affect internal and external coherence (Agolla and Van Lill 2013), innovation activity (Koch et al. 2006), and innovation capabilities (Dixon et al. 2014). Wider conditions fostering innovation, are self-organization (McMillan and Carlisle 2007; Rashmn et al. 2009) and entrepreneurship (Jacquemin and Janssen 2015).

Internal and environmental factors central to this debate (Walker 2007) are discussed below.

\section{Internal and Environmental Influencing Factors}

\section{Internal Factors}

Studies elaborate on different internal interconnected elements that influence innovation and include strategy (Damanpour and Schneider 2006), organizational climate (Walker 2008), leadership, entrepreneurship (Rashman et al. 2009) and organizational competences (Agolla and Van Lill 2013; Chiva et al. 2014). All the foregoing stress that ideas need to be garnered and incubated before implementation begins (Marr 2009). Sufficient time is needed for experimentation before good ideas are deployed, which should also allow for mobilisation of resources and identification of collaboration partners (Akrich 2002; Marr 2009).

Organizational strategy plays an important role in driving innovation in the public sector (Walker 2008). The first step in formulating a strategy is to define what innovation means to the organization. 
Public sector organisations are now driven by strategic management and focus on outcomes, therefore a more rigorous performance management approach is also required (Bryson et al 2014). Strategy provides direction and focuses the efforts of the entire organization on a common goal. To achieve this, all levels of the organization need to be involved to ensure employee buy-in (Damanpour and Schneider 2006; Tessarolo 2007). Poorly communicated strategy will likely create a barrier to innovation and it should not be assumed that employees understand the focus and role of innovation (Agolla and Van Lill 2013; Chiva et al. 2014). Furthermore, the strategy needs to be aligned and integrated with the resources of the organization (Damanpour and Schneider 2009). Information technology needs to be considered, as well as appropriate performance measures (Baden-Fuller and Haelfliger 2013; Sørensen and Torfing 2011).

Organizational climate is concerned with attitudes and beliefs within an organization and should reflect the behaviour of members (Walker 2008). Senior management is expected to drive innovation within the public sector, through governmental support and relevant reward structures in place to enhance employee buy-in and motivation towards innovative behaviour (Ingraham et al 2003; Schoeman et al 2012). Importantly, a short-term view is not enough and the achievements should be considered for long-term results. (Agolla and Van Lill 2013).

Other internal drivers relevant to innovation include intangible organizational competences such as depth of experience of the workforce, its skills and knowledge (Damanpour and Schnider 2006; Agolla and Van Lill 2013). Managing such resources is essential in terms of reward systems and opportunities for personal development. Organizations should invest in human capital, education and training at all levels (Tseng and Abdalla 2006; Esteve et al. 2013).

\section{External Environment}

In the external environment public sector organizations are influenced on three levels: remote environment, industry and operating environment (Agolla and Van Lill 2013). Lewis and Ricard (2014) suggest that the public sector external environment is dynamic, where elements interact and cause and effect is difficult to establish. Key elements to be explored and managed include political, social, ecological, technical, legal environments and collaborative linkages (Agolla and Van Lill 2013; Dr Vries et al. 2016).

Bekkers et al. (2013) identify several aspects of the environment that could be important drivers and barriers to innovation, including the social and political complexity of the environment in which public organizations operate and the relationships between public and private organizations at different levels. More specifically, formal structures that have been previously identified as positively and 
negatively related to innovation capacity (Bekkers et al. 2013), political and administrative triggers such as crises and competition, a decentralised state, corporatist governance traditions, and strong civil society have a positive effect. While a strong formalised, centralised, rule-bound legal culture create negative effects, political decisions that impact on the organization and innovation are usually driven by a need to keep up with public requirements and expectations (Sørensen and Torfin 2011). It is in the interest of political forces to ensure that critical public services continue to run effectively, whilst reducing cost and enhancing customer experience (Walker 2007; UKRN 2015).

Strategic change in the public sector requires top down enforcement of political will, as well as allocation of resources required for substantial change (Damanpour and Schneider 2009; Agolla and Van Lill 2013). Tension arises when employees are required to be creative but also have to comply with rules. Demand for innovative solutions is a driver of innovation, especially when it improves public policy and services. Devolved management drives authority down and encourages lower level managers to experiment and to implement innovations (Walker 2007).

Sørensen and Torfing (2005) highlight that public sector innovations are incremental, often accidental, demonstrating the need for a long term perspective, rather than quick wins. Interestingly, the UK government seems to have acknowledged this and public sector innovation has been given a high profile in the recent years by provision of risk-taking funding to facilitate collaborative innovation (Matthews et al. 2009). There is thus pressure from Government for the public sector to look for innovative solutions and effective and efficient public sector interventions (Agolla and Van Lill 2013).

The public sector is hard pressed to keep up with the rate of technological change. It is a priority of the public sector to design public goods and services that are environmentally friendly and the public expects institutions to be proactive rather than reactive (Matthews et al. 2009).

To address external factors, the public sector needs to explore potential partnerships with key stakeholders, such as customers and private organizations, which requires a certain level of openness regarding the innovation process (Collm and Schedler 2014; De Vries et al. 2015).

\section{The role of collaboration in fostering public sector innovation}

Innovation requires collaborative interaction (Rashman et al. 2009) when exploring innovation challenges and a key issue is the degree to which institutions collaborate (Esteve et al. 2013). Innovation as a result of collaboration is complex and is not always driven by social or political actors (Sørensen and Torfin 2011). Collaboration may be fostered within the organization by entrepreneurial individuals making decisions within a formalised system of rules and procedures (Walker 2007; Meijer 2014). Thus, the level of innovation in the public sector depends on how well it can manage 
collaboration, internally and externally to create value, reduce barriers and harness resources within cooperating organizations (Ingraham et al. 2003).

Activities such as formal audits and memos contribute to effective retention and application of knowledge. This facilitates learning from past projects (Esteve et al. 2013). Activities that promote learning in the firm's strategic context help uncover new applications of existing knowledge and directly increase innovation performance (Marsh and Stock 2006).

In order to encourage collaboration, public sector organizations should support free flow of information, dispel fear of failure and expand knowledge by sharing ideas through stakeholder engagement (Walker 2007; Agolla and Van Lill 2013). External knowledge is promoted by partnerships, alliances and joint ventures, research and development and licencing (Chesbrough 2003). This requires effective intellectual property arrangements, not only to identify external knowledge, but create value by leveraging an organization's intellectual knowledge.

Such activities involve public and private groups and require effective communication and specialised competences on the part of participants (Sørensen and Torfing 2011). It opens up the innovation cycle to many actors by tapping into innovation resources across borders, overcoming restrictions and creating support for innovation (Lewis and Ricard, 2014). Regulatory intervention may well be a key mitigating factor in overcoming many of these challenges. Collaboration with private partners may be a way to address societal challenges as changes in governance receives more attention (De Vries et al. 2015). Such an approach sees public value creation by involvement of stakeholders from the community and accountability in a collaborative environment (Bryson et al. 2014).

Innovation activities are strongly influenced by national policy and vitality of public institutions (Porter and Stern 2002). Therefore, Government should create receptive conditions that stimulate innovation by legislation, policies and regulations (Stewart 2010; Agolla and Van Lill 2013).

\section{Influence of Regulation on Innovation}

Despite the perceived need for Regulators to intervene in pursuit of innovation, Regulators recognise that regulation may impede innovation (Lyon 1995; Sørensen and Torfing 2011; UKRN 2015). Traditional regulations restrict potential profitability in exchange for reducing risk of loss. The threat of retrospective review may force a utility to switch from an innovative technology to the more costly conventional one (Dewar and Dutton 1986; Lyon 1995). Radical innovation that yields greater benefits, but is risky and costly, explains why incremental innovation is more attractive as a means of regulation compliance, despite the obvious benefits of radical innovation (Stewart 2010). 
Economic theory states that regulations impose a cost burden causing firms to reallocate spending away from innovative investments (Stewart 2010). The environmental movement, along with greater public concern for social health and safety holds that economic efficiency may be a necessary sacrifice for improved social welfare. This has led academics to explore the role of regulation in wider contexts (Bryson et al. 2014). Suggestions for Regulators to improve innovation and adoption of innovative technologies include profit-sharing, yardstick competition (comparing utilities) and prospective prudence reviews (Lyon 1995; Matthews et al. 2009; UKRN 2015). This implicitly indicates a commitment to move from a prescriptive regulatory regime towards a system-based approach (Mills and Koliba 2015).

Regulation should be flexible, allowing the firm and the market to decide the optimal path to implementation. Regulation should also be expedient, both in implementation and execution, and unambiguous, minimising the uncertainty facing firms when bringing new products or processes to market (Stewart 2010). Regulators should also recognise opportunities to reduce information asymmetry in the market, or even to provide expert knowledge in collaboration with industry in order to aid the innovation process (UKRN 2015). The elementary lesson however, is that regardless of the impact of regulation on innovation, if Regulators place innovation at the forefront of their policy goals along with distribution, fairness, and environmental concerns, this should improve innovative potential (Stewart 2010) and support a move towards a more performance based regime (May 2007).

\section{The role of regulatory regimes and accountability}

Noting how regulation negatively impact innovation, scholars and policy makers are exploring frameworks that may facilitate innovation potential in diverse economic sectors (Collm and Schedler 2014). Blind et al. (2004) argue that policy makers have shifted focus towards the regulatory framework as a means of promoting innovation. This means that within self-regulating partnerships and networks, actors are able to negotiate and amend rules within the regulatory framework (Sørensen and Torfing 2011). Interestingly, there is no clear agreement as to how the regulatory framework may be redefined to promote greater innovation generally. As Koop and Lodge (2015: 11) have found when exploring the nature of regulation, "regulation is about intentional intervention in the activities of a target population." They further summarise that there are three key conceptions of regulation: (1) rules and mechanisms to monitor and promote compliance, (2) mechanisms to manage economies and (3) processes of social control. These concepts seem to support the notion of regulatory regimes outlined by May (2007), where prescriptive regimes depend on rules and compliance, system-based regimes encompass processes and managerial aspects of regulation and performance-based regimes relating to social control through collaboration and outcome-based 
practices. While literature suggests that there is a trend towards more collaborative regimes, this however appears to increase the complexity of the regulatory environment, due to the increased number of actors involved (May 2007; Mills and Koliba 2015). The accountability of those who enforce regulations becomes increasingly important (Ebrahim 2003; May 2007; Molnár 2008).

Relatively little academic thought is directed towards accountability in this context. May (2007:11) summarises "it must be considered a multilevel concept within a devolved regulatory state", that encourages regulatory transparency and accountability. A regime is made up of an institutional structure and assignment of responsibilities for ensuring regulatory action and involves aspects of legal, bureaucratic, professional and political accountability (May 2007). Mills and Koliba (2015) suggest that collaboration including customers and shareholders, should ensure that regulatory decisions are driven not only by profit, but also by reputation, social norms and customer satisfaction.

Traditionally, government focusing on rules and regulations that demand compliance may constrain an innovative environment for stakeholders by focusing on maintaining status-quo within the regulatory frameworks (Mills and Koliba 2015). In order to facilitate innovation, alternative regimes are proposed, that encompass collaboration and shared accountability. May's (2007) work is considered a comprehensive analysis of accountability within regulatory governance networks (Mills and Koliba 2014). May (2007) describes levels of accountability as follows: (1) Legal accountability relates to fair and appropriate rules and standards; (2) Bureaucratic accountability requires regulated entities to comply with regulatory requirements and to take into account non-compliance; (3) Professional accountability concerns with the appropriate exercise of professional judgement; (4) Political accountability is about shortfalls in the regulatory regime being acknowledged and necessary adjustments made.

It is important to note that although system-based and performance-based regulatory regimes are being adopted more widely, they cannot be removed entirely from traditional prescriptive regulatory regimes, as these ensure accountability of Government towards citizens (May 2007). The move towards shared accountability reduces the traditional role of Regulators, as reliance on professional expertise of stakeholders becomes more important (May 2007). The transition between different regulatory regimes are thus formalised, whilst enabling movement across regimes. This requires capabilities that support experimentation and collaborative processes, risk taking and project management across the stakeholder network (Dixon et al. 2014). 
From this perspective, Regulations can be viewed as innovation enablers, mediating the influencing factors to support innovative behaviour. Scope for innovation is enhanced by movement from prescriptive to performance-based regimes. Accountabilities are acknowledged via collaborative mechanisms, which support stakeholder engagements that encourage regulatory transparency and governance (Mills and Koliba 2015).

\section{Method}

This study employs a critical case design to build upon existing literature and theory on the impact of regulation on innovation in the Scottish Water sector (Yin 2013).

Regulation of the Scottish water industry is complex and the Water Industry Commission's role is to make the industry more effective and open to public scrutiny. The Water Industry Commission is responsible for promoting the interests of customers of Scottish Water. Other stakeholders involved include:

- $\quad$ The Scottish Environment Protection Agency (SEPA), which monitors compliance and issues consents for the discharge of wastewater, as well as working with Scottish Water on developing water improvement plans.

- $\quad$ The Drinking Water Quality Regulator (DWQR), which protects public health by ensuring compliance of drinking water quality regulations.

The Scottish Parliament holds ministers and Scottish Water, SEPA and WIC to account for performance (Audit Scotland, 2005; Scottish Water Annual Report, 2013/14).

Scottish Water was established in April 2002 from a merger of three previous water authorities and is responsible for providing water and water services to households and businesses. As a "public corporation of a trading nature", it is expected to behave as a commercial organization, although it has no shareholders. The motivation for the creation of Scottish Water was to make the Scottish water industry more efficient, competitive and to improve value for money as a result of economies of scale. The move was designed to introduce innovation, improve customer service and reduce costs (Audit Scotland, 2005; Scottish Water Annual Report, 2013/14).

As a public sector monopoly, robust regulation is appropriate but it also needs to provide conditions where those involved can cooperate to ensure transparency and innovation to minimise regulator costs. The Scottish water industry has undergone transformation in recent years through the introduction of innovative approaches such as the introduction of retail competition and the customer negotiated settlement model. Accordingly, the Scottish Water Innovation Panel, was set up between August 2013-2015 to review the industry's approach to innovation and assess opportunities to 
enhance innovation. Findings suggested that the industry was in an early stage of evolution regarding innovation and there was a need to grow a stronger innovation culture across the industry. The report stated that there "is a need to come together to formalise arrangements to ensure that all parties work together effectively in the future, providing an environment that stimulates innovation" (Scottish Water Industry Innovation Panel, 2015, p3).

The research approach taken to explore this was a qualitative case study, which according to Blind (2012: 391) is "appropriate to analyse the influence of the regulatory framework on innovation in very specific markets." The work was commissioned by the Water Industry Commission for Scotland (WICS) in order to determine how the Commission might better support innovation. WICS arranged access to the executives in the main stakeholder network and involved representatives from all regulatory bodies, government, the main water provider and consumers.

The proposed framework applied to the context of the Scottish water sector drew upon the systematic literature review of Agolla and Van Lill (2013) and De Vries et al's. (2016) heuristic model for public sector innovation.

The research comprised two phases: a literature review, followed by interviews with senior executives in all stakeholder organizations within the Scottish water sector. The interview protocol followed the main constructs set out in the conceptual framework (see figure 2 for the main themes and associate literature sources).

Insert figure 2

Respondents were purposefully selected based on length of service and experience within the sector. To capture diverse perspectives, the respondents came from cross-disciplinary areas, including strategy, water management and consumer representatives. Overall, 12 interviews were conducted and in order to ensure accuracy, two interviewers were present at each interview. Recordings of interviews were supported by detailed interviewer notes. Transcripts were coded according to the key themes identified in the literature. In the first instance, coding was done by the research team independently and followed by cross-checking to ensure accuracy of interpretation. Intercoder reliability (Miles and Huberman, 1994) was moved from 70 to 90 per cent over the course of the coding process.

In addition, government documents, media reports, annual reports and organizational documentation were reviewed to triangulate the interview data and provide support for statements made in relation to defining innovation, external influences and stakeholder collaboration. 
Following on from this, themes related to Agolla and Van Lill's (2013) and De Vries et al. (2016) were evaluated to consider sector network innovation level. Then, potential related to the regulatory regimes framework (May 2007) was noted and overlaid in a matrix showing how the case data mapped onto regulatory regimes and accountability levels. Integration of the frameworks reflected the different stages of regulatory compliance, from prescriptive to performance-based outcomes and measures within the sector.

\section{Findings: Regulatory influences on innovation in the Scottish Water Sector}

Historically, public sector regulation has been viewed as having a negative impact on innovation within the water sector. Recent changes in regulatory practice, organizational culture and engagement with customers are encouraging more innovation focused orientation. At the same time, drawbacks/barriers still need to be addressed to further support such innovation. The following describes how innovation is demonstrated in the Scottish water sector, the influence of internal and external factors, the role of collaboration, the Regulator as the innovator and the impact of regulation on innovation. This is then mapped onto the original figure 1 demonstrating how the regulator can allow regulated organisations to be more innovative through the mobility across regulatory regimes.

\section{How has innovation been demonstrated?}

9 out of the 12 interviewees identified lack of a common perception of innovation by water sector stakeholders. When prompted to define innovation, one respondent suggested that, "Improvement is not seen as innovation, but rather business as usual."

This comment appears to be in line with the water sector operating in a reactive, problem-solving mode, where incremental changes are not seen as innovative. Another interviewee emphasised that "above all innovation has its genesis in cost reduction and suffers because of a preoccupation with risk and old style technology development processes." This view is reinforced by others who note that "cost savings is the driver behind innovation," and "innovation has been about solving problems and was not about on-going improvement or new discovery".

There is no common vocabulary describing the meaning of innovation by key stakeholders in the sector. While efficiency and saving money has been the driving force, despite this rather pessimistic perspective, technical innovation can be demonstrated. For example, in waste water treatment; in the labs concerning cryptosporidium or disinfectant bi-product and phosphate removal. "A lot of work has been done in the supply of drinking water and we are always looking at new ways of doing things, but this is not seen as innovation, but business as usual." While the sector is undoubtedly innovative 
"it thinks in terms of continuous improvement, rather than innovation and there is a lot going on but it is not necessarily considered innovation."

Internal Influence on Innovation

All respondents agreed that progress has been made towards encouraging innovation culture. "The signs of an emerging innovation culture are there with a developing sense of responsibility towards innovation." The potential impact of innovations has not been fully grasped and there has been "too much faith in certain types of innovation such as incremental as opposed to radical or disruptive." Tension exists between first, the need for innovation and second, risk management requiring "more collaboration with local government, especially as low risk tension exists."

Most respondents identified the main operations and maintenance provider as key to encouraging greater innovation within the organization. "[The organization] is less entrenched than it used to be, they are quicker to react, self-aware and honest and putting the right people in to improve the culture." Although four respondents praised the entrepreneurial mind-set by the provider, they also indicated that further work is needed to capture and reward creative problem-solving and innovative approaches to work currently done by employees as part of their normal job. "Innovation is not communicated well enough, it is not diffused efficiently."

One respondent pointed out that "the water sector is still populated by an engineering mind-set and a traditional human resource type, leading to a comfort zone and narrow thinking style." Further, it was noted that change within the key organizations needs to be managed strategically. For example, "every manager must include innovation on their monthly agenda" and "better collaboration is required" involving major players across the stakeholder network. "Experimentation is often off-line and under the radar", so whilst trial and error has produced results there is a requirement to think and act more collaboratively.

Innovation success is inadequately communicated across the sector and that includes Government at Ministerial level. A quote from a respondent indicates that "[they] manage innovation internally, and as a result Government never hears about it." This is exacerbated by "ministers being risk averse and wanting answers immediately." This inhibits innovation motivation, as key stakeholders continue to emphasise compliance and use of established methodologies. Risk aversion and fear of failure driven by Government is a major inhibitor to innovation in the sector.

Influence of external factors on Innovation

Similar issues arise when exploring the influence of the external environment on innovation in the Water sector. The overarching influence of Ministerial decision making and attitude is seen as the 
significant inhibitor to a more adaptive approach to problem-solving. All of the respondents pointed to short-termism by ministers, micromanagement of localised issues and risk mitigation. Tension exists between the requirement to innovate and the necessity for risk management and any future strategy must recognise this. Currently, the emphasis towards problem solving depends on "costbenefit in order to ensure compliance", however it is recognised that "a move from current output mentality to outcome driven solutions and a more experimental culture" is needed. Mirroring the internal perceptions by the respondents, similar themes arise when discussing external influences. A need for "breaking ingrained behaviour, overcoming established perceptions, developing a shared vison and sharing outcomes" is fundamental to overcome barriers.

As well as economic drivers, social factors significantly influence innovation. As the Regulator fully recognises the essential of ensuring public health at all times, the imperative for compliance is maintained as the key driver when revisiting regulation. This should not however inhibit innovation, but aims to promote continuous improvement. New ways of thinking and problem-solving lead to better understanding of different social concerns (such as rural water supply and management) and more advanced technical solutions. One respondent stressed that "process and technology innovation must have an impact on, and benefit to, the customer", which means that improvements should be visible across the Scottish Water sector. It has been recognised by respondents that the Regulator has a unique opportunity to consider a cross-industry context to facilitate creation of added value across the network by "work more closely with SMEs, universities, energy utilities and local authorities."

\section{The Role of Collaboration in Innovation}

All agreed that while collaboration between stakeholders is improving, this tends to be at a high level and does not fully cascade down to operational levels. As respondents pointed out, there are still circumstances inhibiting cross-functional integration. Respondents emphasised that collaboration should extend beyond their own organization, as "Involvement of supply chain can add value." Propositions for improvement coming from respondents include prioritising collective thinking to promote innovation. This has been acknowledged in part by the establishment of a UK Water Partnership, which "although not yet matured, offers a forum to coordinate strategy, SME linkages and R\&D investment."

Another example of effective collaboration is the customer forum, which ensures that "the customer voice is now at the heart of the decision making process." Other respondents support the conclusion that the customer forum is working well and acknowledge the customer voice, but emphasise the need to "continue the move away from the telephone, to online and real time feedback." Such forums are important to maintain and encourage dialogue between key stakeholders and to understand their 
needs in relation to service costs. At the same time there has to be more innovation within the framework. Engaging in dialogue with the customer ensures the right information is shared between provider and customers. This involves understanding and acknowledging risks in providing new, improved solutions to water supply and management. As one of the respondents points out "Customers will take a certain level of risk, but they must understand the risk."

This attests to the readiness of stakeholders to move beyond established practice. Most interviewees mentioned experimentation and blue-sky thinking as integral to collaborative practices. The focus is still on risk and compliance, but with a change in the way funds are allocated, "is allowing a movement beyond incremental, continuous improvement, towards a more radical innovation." However, it is acknowledged that blue-sky thinking has a longer lead time and may not pay-off within a regulatory period. This still presents a challenge to the Regulator, Ministers and the extended supply chain, because there may not be an immediate return.

Furthermore, a risk averse culture does not support such experiments. Because there is no room to fail, sector stakeholders are inclined to maintain the established practices that are safe and within the compliance framework. Collaboration needs to be funded enabling the sector to work more closely with external bodies and associates such as universities and local authorities. That is a more open approach to solving radical innovation problems.

Regulator as Innovator

All interviewees recognised steps the Regulator has already taken by providing incentives that encourage innovation; including a customer forum, innovation panel and rolling-reviews. One example cited by respondents relates to the negotiated settlement, which is considered to be "hugely innovative, and measures the delivery of the capital programme." However, "while the six year regulatory period has helped innovative approaches, consideration needs to be given to longer term planning perspectives in order to mature thinking in innovation."

The Regulator is constrained by tight parameters set by government "but is very open to new areas of dialogue." In this sense, the Regulator can be viewed as innovative by encouraging innovation capability and communication initiatives such as the customer forum, innovation panel and rolling review process, "WICS is a regulator prepared to innovate, it has an open and creative mind-set and very capable of innovating." Although the focus is still on risk and compliance, the regulatory process previously based on CAPEX and OPEX has now moved to TOTEX, "this has released funds, allowing movement beyond incremental continuous improvement towards radical innovation." This measures the delivery of the capital programme and "is very novel" with customer experience measured in both business and households. Accordingly "there has been a massive transformation from a drive to achieve regulatory targets to continuous improvement." 


\section{Impact of Regulation on Innovation}

In terms of encouraging innovative behaviour and a greater focus on customer requirements "the regulatory methodology from WICS has changed and there are less regulatory absolutes, which has given more space for talking to customers." Respondents recognised that opportunity exists within the regulations "to transfer or share risk ownership from the regulator to the key stakeholder organizations in the water sector." Working in partnership to manage risk in terms of "sharing between involved parties, where checks and balances and risk management could be employed to exceed standards." Longer term innovation is challenging because radical innovation may not pay-off within the regulatory period and government is likely to get involved in minute detail at local level and "will not be prepared to accept failure or bad publicity." This is contradictory to long-term planning and in order to mature innovation thinking, there is a need to "move from and outputs mentality to and outcome driven solutions and a more experimental culture." This requires learning by trial and experimentation, trying new technologies and seeking external advice beyond industry or national boundaries, as well as working more closely with other utilities. The following discussion section draws on literature to analyse the findings from the scoping study.

\section{Discussion}

Crucial for life and industrial processes, water itself represents only a small portion of overall production costs in the water industry, security of supply and transportation outweigh other cost considerations (Granger 2007). These realities influence providers to satisfy the needs and wants of key stakeholders. Tension exists, between the need for innovation and the need for risk reduction (Stewart 2010). Alleviating risk tension lies at the heart of the matter and all parties interviewed expressed a willingness to do so and a desire to understand the nature of risk in more depth (Brysted and Hensen 2015). While historically regulation has impacted negatively on innovation, modifications in regulatory practice (Stewart 2010), organizational culture (Walker 2008) and customer engagement (Bryson et al 2014) within the water sector seem to be changing this and driving towards a more innovation focused future.

Regulation does influence innovation due to the need for compliance but on the other hand the Regulator, supports new mechanisms that create impetus for innovation across the sector. Stewart (2010), summarises two competing ways in which government regulation impacts innovation. First, regulation places a compliance burden on firms which causes them to divert time and money from innovative activities. Counter to this, regulation may spur either compliance innovation, which occurs when the scope of regulation is broad and the resulting product or process innovation remains within 
the scope of regulation or circumventive innovation, which occurs when the scope of regulation is narrow and the resulting innovation allows firms to escape regulatory constraints.

This study clearly establishes that the water sector in a compliance innovation environment and that all stakeholders need to take advantage of the potential setting. WICS was singled out by respondents as generally supportive of innovative thinking and is seen to have good collaborative relations with providers and Scottish Government (Walker 2007; Collm and Schedler 2014).

The role of government and regulation in shaping the external environment has been identified as the main mechanism to enhance innovation in the sector (Rashman et.al. 2009). An example of this is the Water Framework Directive that provides much more room for innovation within reasonable timescales and this challenging thinking could spread to include renewables, climate change, sustainable wetlands and rural provision.

Greater collaborative dialogue and shared risk understanding between and amongst core stakeholders is required - and that 'longer views' across strategic risk planning are also a requisite (Walker 2007). Ideas need to be incubated and managed in order to encourage collaboration (Sørensen and Torfing 2011). This highlights the need to properly define innovation within the stakeholder group (De Vries et. al. 2016), placing the end customer at the centre of innovation. Innovation itself seems limited to linear, incremental pathways, cost efficiency, symptom fixing and reaction. More must be done to broaden experimentation, widen scope in methodology and mobilise slack resources to transform innovation into value creation (Damanpour and Schneider 2009).

Shouten and Van Dijk (2010) explore the constraints and opportunities posed by regulatory regimes and the water provider's discretion when dealing with clients, by offering products/services, setting tariffs, organising themselves and establishing relationships with users. Research indicates that the regulatory context invites water providers to differ in their market strategies, product and tariff setting. The regulatory context seems to be indeterminate in respect of internal and external organization. This indicates that internal and external innovation drivers, as identified above, can be implemented independently of the regulatory system and depend on internal innovation capacity of organizations (Agolla and van Lille 2013).

Where regulation comes to play as identified by WICS (2013), is via the regulatory regimes that support compliance through outcome-based measures of performance and greater engagement with customers. This supports innovative behaviour, as it enables better understanding of the impact of "higher-risk" radical innovation, as well as lower cost, incremental solutions in the course of adopting new improvements (Sørensen and Torfing 2011). 
The foregoing requires collaboration between the regulated firm and the Regulator in order to foster free exchange of information and trust building. This further emphasises the transition from the prescriptive regulatory regime towards a performance-based regulatory one (Mills and Koliba 2015). Figure 3 demonstrates this transition for the studied case.

Insert figure 3

The findings related to innovation in the public sector are translated into the regulatory regimeaccountability matrix, as proposed by May (2007). This integration highlights collaborative mechanisms that facilitate open dialogue that support movement across the regimes for the studied industry. In this sense the regulation may be considered innovative in the way innovation is encouraged and the impact of regulation on innovation can be conceptualised via activities and practices that support mobility across the regulatory regimes.

Due to the nature of the sector, the transition occurs on bureaucratic, professional and political levels. The Regulator can only progress towards a system-based regime, as compliance to health standards remains paramount. The move towards a performance-based regime requires stakeholders to progress by encouraging exchange of information, development of self-regulation and establishment of trustworthy relationships within their networks (Mills and Koliba 2011). As the customer becomes more involved in developments within the sector, societal pressure increases and stakeholders are driven to establish standards beyond compliance that foster innovation (van Erp 2011).

Collaborative accountability binding the stakeholders becomes crucial to the management of reputational capital and is the glue that binds network relationships necessary to promote selfregulation (Mills and Koliba 2015). In the case of the Scottish Water Sector the Customer forum serves to ensure that links between Regulator, regulation and stakeholders remain transparent. In this way citizen confidence is fostered with a clear overview of relationships between key actors within the regulatory regime.

The findings demonstrate that customer and shareholder accountabilities are actually manifested at the transitional interfaces of the regulatory regimes, that is through the customer forums, partnership initiatives and joint KPIs that support the collaborative practices, which facilitate movement within and in-between the systems. There is a continuous interplay within the accountabilities and thus ongoing adjustments to the regulatory regime are paramount for progress. Through incentives for establishing partnerships, the Regulator provides conditions where new ideas can emerge without the risk of failure, also experimentation can drive new approaches solving existing problems (Samford, 2014). Accountability has become multifaceted and a more inclusive dialogue is emerging that incudes 
community stakeholders from many sectors have become more involved in the decision making (Bryson 2014). Movement from prescriptive compliance to performance based outcome measures requires transparent accountability across the regulatory regimes (Ebrahim 2003).

\section{Conclusion}

The aim of this study was to explore the influence of regulation on innovation behaviour in a highly regulated public sector environment, i.e. the water sector in Scotland, in order to identify and evaluate factors impacting on innovative behaviour. The research approach was qualitative and in two phases, a literature review and interviews with senior level executives within the sector.

Due to risk averse culture promoted by regulation, innovation is governed by risk management practices. This is sector specific due to the public health risk from poorly regulated supply and management. Initiatives have been undertaken by the regulatory authority to promote innovation alongside revised practices that devolve some authority to participating institutions, although the development of intervention practices is still in its infancy.

The basic imperative for the sector is to have a common understanding of exactly what this innovation is, who plays what role, when and how. Initially, greater focus was on engaging in technological innovation, although participating institutions acknowledged that business process innovation and continuous improvement in general also contributed. The need exists to establish a joint innovation process across the water sector that would enhance both business and engineering practices within the sector.

Attitudes to risk also arose due to involvement and prioritisation driven by Government. This caused some tension between involved institutions and was acknowledged as a potential barrier to strategic innovation. Additionally, publicity seemed to play a key role in highlighting the risk to government reputation and the tension between potential reputational risk, compliance regulation and innovation; leaving no opportunity for experimentation or the possibility of failure.

Our findings suggested that while regulation influences innovation in the sector, on the one hand there is a clear need for compliance and on the other economic factors are driving innovation throughout the sector. Tension related to risk mitigation, indicated that further emphasis needs to be placed on collaborative approaches to risk management.

The scoping study confirmed that different attitudes and tolerance to risk are endemic. The WICS regulatory body provides mechanisms in support of innovation and core stakeholders express clear motivation to open dialogue and share common approaches to risk management within the regulatory framework. 
Research is always subject to limitations and future research would benefit from exploring an overarching definition of innovation related to the sector, processes and mechanisms to drive innovation and key roles and structures that would allow for effective prioritisation and more performance-based regulation.

The guiding question for this paper was: "To what extent, if any does a regulatory framework inhibit innovation within the public sector environment?" Through the integration of two theoretical frameworks and their preliminary test within the Scottish water sector the following movements across regimes to drive innovation can be acknowledged:

1. Stakeholder collaboration across the network enables clear understanding of roles, responsibilities and resources necessary for promoting an innovative culture across the industry. Prioritising projects and identifying human resource talent becomes interdisciplinary, encourages entrepreneurial behaviour and is needs driven, rather than short-term politically oriented.

2. The Regulator and Government must share responsibility for allowing risk and managing uncertainty in order to promote experimentation and forward-thinking in the network organizations. Other stakeholders would however, be required to maintain regulatory governance within the network related to the implementation of self-reporting, self-auditing and quality control processes to drive the transition to performance oriented outcomes as represented by accountabilities in figure 3 .

3. Compliance is tacit and explicit in all regulations and the Regulator provides the structure to enable innovation beyond established protocols. In this sense, the Regulator becomes the driver of innovation, providing the overall strategic direction, but leaving the opportunity for new creative solutions. This implies that regulations can be both absolute and discretionary, allowing room for continuous development and radical innovation. There are however, tradeoffs between key stakeholders related to sharing risk. This depends on accountability for problem solving, ability to fail and the need for leadership so as to enable the shift from prescriptive command and control rules to a more performance-based regulatory regime.

It is clear that the Regulation within the Scottish water sector supports innovation orientations within the main companies in the network. Risk management and ministerial intervention remain the most dominant barrier to radical innovation. The scoping study presents two contributions:

(i) From a theoretical perspective, we believe this is the first research to provide empirical evidence of the mechanisms for transition across regulatory regimes using accountability levels set out by May (2007). 
(ii) From a practitioner point of view, the study supports the notion that moving from prescriptive based to performance based regulatory regimes requires collaboration with key stakeholders in the network. Such collaborations bring together wider viewpoints, encourage information sharing and trust building that is "Innovation is the art of interesting an increasing number of allies who will make you stronger and stronger" (Akrich et al 2002, 189).

Mobility across the regimes is conceptualised by finding the right collaborative practice and mechanisms to promote the widest dialogue while ensuring accountability of all involved stakeholders. Greater stakeholder involvement and accountability means that innovation can take place more freely within the regulated context. The matrix demonstrates how the regulatory regimes might mediate relationships between accountability levels and regimes to support increased levels of innovation within the sector. Through incentives for establishing partnerships, the Regulator is providing conditions for new ideas to emerge with reduced risk of failure. Regulation becomes a vehicle for opportunity supporting both incremental and radical innovation behaviour.

\section{References}

Audit Scotland (2005). "Overview of water industry in Scotland." Accessed on 5.5.2017 at: http://www.audit-scotland.gov.uk/docs/central/2005/nr 051013 water overview.pdf

Agolla, E.J. and Van Lill. B.J. 2013. "Public sector innovation drivers: A process model”. Journal of Social Science, 34 (2): 165-173.

Akrich, M., Caollon, M., Latour, B. and Monaghan, A., (2002), "The key to success in innovation Part 1: The art of interessement", International Journal of Innovation Management, 6(2):187-2006

Baden-Fuller C. and Haefliger S. 2013. "Business Models and Technological Innovation". Long Range Planning, 46: 419-426.

Barczak, G., A. Griffin and K. B. Kahn. 2009. "PERSPECTIVE: Trends and Drivers of Success in NPD Practices: Results of the 2003 PDMA Best Practices Study". Journal of Product Innovation Management 26 (1): 3-23.

Battisti G., and Stoneman P. 2010. "How innovative are UK firms? Evidence from the 4th UK Community innovation survey on synergies between technological and organizational innovations." British Journal of Management, 21: 187-206. 
Bekkers, V.J.J.M., Tummers, L.G. and Voorberg, W.H. 2013. From public innovation to social innovation in the public sector: A literature review of relevant drivers and barriers. Rotterdam: Erasmus University Rotterdam.

Blind K. 201). "The influence of regulations on innovation: A quantitative assessment for OECD countries". Research Policy, 41, pp 391-400.

Blind, K., Buherlen, B., Kotz, C., Menrad, K. and Walz, R., (2004). New Products and Services: Analysis of Regulations Shaping New Markets. European Commission DG Enterprise, Luxemburg.

Borins, S., (2001). Encouraging innovation in the public sector, Journal of Intellectual Capital, 2(3): 310-319.

Bryson, J.M., Crosby, B.C. and Bloomberg, L. 2014. “Public value governance: Moving beyond traditional public administration and the new public management". Public Administration Review, 74 (4): 445-456.

Bysted, R. and Hansen, RJ. 2015. “Comparing public and private sector employees' innovative behaviour: Understanding the role of job and organizational characteristics, job types and subsectors". Public Management Review, 17 (5): 698-717

Candi, M., van den Ende, J., Gemser, G. 2013. “Organizing innovation projects under technological turbulence". Technovation, 33: 133-141.

Chesbrough, H. 2003. Open Innovation: The New Imperative for Creating and Profiting from Technology. Boston: Harvard Business School Press.

Chiva R., Ghauri P. and Alegre J. 2014. “Organizational Learning, Innovation and Internationalization: A Complex System Model". British Journal of Management, 25: 687-705.

Collm, A. and Schedler 2014. "Strategies for introducing organizational innovation to public service organizations". Public Management Review, 16 (1): 140-161.

Damanpour F. and Schneider M. 2006. Phases of the Adoption of Innovation in Organizations: Effects of Environment, Organization and Top Managers. British Journal of Management, 17: 215-236.

Damanpour, F. and Schiender, M. 2009. "Characteristics of innovation and innovation adoption in public organistions: Assessing the role of managers." Journal of Public Administration Research and Theory, 19 (3): 495-522.

De Vries, H., Bekkers, V. and Tummers, L. 2016. "Innovation in the public sector: a systematic review and future research agenda." Public Administration, 94 (1): 146-166 
Dewar, R.D. and J.E. Dutton. 1986. The Adoption of Radical and Incremental Innovations: An Empirical Analysis, Management Science. 32 (11): 1422-1433.

Dixon S., Meyer K. and Day M. 2014. "Building Dynamic Capabilities of Adaptation and Innovation: A Study of Micro-Foundations in a Transition Economy". Long Range Planning, 47: 186-205.

Ebrahim, A. 2003. "Making sense of accountability: conceptual perspectives from Northern and Southern nonprofits". Nonprofit Management and Leadership, 14 (2): 191-212.

Esteve M., Boyne G., Sierra V. and Ysa T. 2013. “Organizational Collaboration in the Public Sector: Do Chief Executives Make a Difference?" Journal of Public Administration Research and Theory, 23 (4): 927-952.

Granger, J.D. 2007. "Clark, Duncan and Roger Ford: the crises of innovation in the water and wastewater. Knowledge Technology Policy, 20: 211-13.

Hughes A., Moore K. and Kataria N. 2011. Innovation in Public Sector Organizations: a pilot survey for measuring innovation across the public sector". NESTA Index Report, March.

Ingraham, P.W., Joyce, P.G. and Donahue, A.K. 2003. Government Performance: Why Management Matters. Baltimore: John Hopkins University Press.

Jacquemin A. and Janssen F. 2015. "Studying regulation as a source of opportunity rather than as a constraint for entrepreneurs: conceptual map and research propositions, Environment and Planning C: Government and Policy, 33: 846-862

Koch P, Cunningham P, Schwabsky N, and Hauknes J. 2006. "Innovation in the Public Sector". Publin Report No.D24. From <http www.Step.No/Publin/Publinpost/Index. Html.> (Retrieved on April 11, 2015).

Koop C. and Lodge M. 2015. "What is regulation? An interdisciplinary concept analysis". Regulation and Governance, doi: 10.1111/rego.12094.

Lewis J.M. and Ricard L.M. 2014. "Innovation capacity in the public sector: structures, networks and leadership". LIPSE project working paper no 3

Lu, I., Chang, T. 2002. "A contingency model for studying R\&D - marketing integration in NPD." International Journal of Technology Management, 24, (2-3): 143-164.

Lyon T.P. 1995. "Regulatory hindsight Review in Innovation by electric utilities". Journal of Regulatory Economics, 7: 233-264. 
Marr B 2009. Managing and Delivering Performance: How Government, Public Sector and Not-ForProfit Organizations can Measure and Manage what Really Matters. Oxford: Elsevier Ltd.

Marsh, S. J. and G. N. Stock. 2006. "Creating Dynamic Capability: The Role of Intertemporal Integration, Knowledge Retention, and Interpretation." Journal of Product Innovation Management $23(5): 422-36$.

Matthews M., Lewis C. and Cook G. 2009. Public Sector Innovation: a review of literature. ANAO. May J. P. 2007. "Regulatory regimes and accountability." Regulation and Governance, 1: 8-26. McDermott A. M., Fitzgerald L. and Buchanan D. A. 2013. "Beyond Acceptance and Resistance: Entrepreneurial Change Agency Responses in Policy Implementation". British Journal of Management, 24: S93-S115.

McMillan E. and Carlisle Y. 2007. "Strategy as Order Emerging from Chaos: A Public Sector Experience". Long Range Planning. 40: 574-593.

Meijer, A.J.2014. "From hero-innovators to distributed heroism: an in-depth analysis of the role of individuals in public sector innovation". Public Management Review, 16 (2): 199-216.

Miles, M. and Huberman, A. M. 1994. An Expanded Sourcebook Qualitative Data Analysis (2nd edn). Thousand Oaks, CA: Sage Publications.

Mills R.W. and Koliba C.J. 2015. "The challenge of accountability in complex regulatory networks: The case of the Deepwater Horizon oil spill". Regulation and Governance, 9: 77-91.

Molnár, M. 2008. "The accountability paradigm: standards of excellence: theory and research evidence from Hungary". Public Management Review, 10 (1): 127-137.

Porter ME, and Stern S. 2002. National Innovative Capacity. In: The Global Competitiveness Report 2001-2002. New York: Oxford University Press, pp. 102-118.

Rashman, L., Withers, E. and Hartley, J. 2009. “Organizational learning and knowledge in Public service organizations: A systematic review of the literature." International Journal of Management Review, 11(4): 463-494.

Samford S. 2014. "Innovation and public space: The developmental possibilities of regulation in the global south". Regulation and Governance, doi:10.1111/rego.12077. 
Schouten M. and van Dijk M.P. 2010. "Regulation and comparative discretion of publicly and privately owned water companies in The Netherlands, England and Wales". Water Policy, 12: 248259.

Scottish water Industry Innovation Panel (2015). "Innovation - a Shared vision." Accessed on 5.5.17 at:

http://www.watercommission.co.uk/UserFiles/Documents/Innovation\%20Panel\%20Final\%20Report \%20and\%20Recommendations 1.pdf

Sørensen, W. and Torfing, J. 2011. "Enhancing collaborative innovation in the Public Sector". Administration and Society, Nov: 1-27.

Stewart L.A. 2010. "The impact of regulation on innovation in the United States: a cross-industry literature review." Information Technology and Innovation Foundation. www.iom.edu/hitsafety Tessarolo, P. 2007. "Is Integration Enough for Fast Product Development? An Empirical Investigation of the Contextual Effects of Product Vision." Journal of Product Innovation Management 24 (1): 6982.

Tseng K.C. and Abdalla H. 2006. "A novel approach to collaborative product design and development environment". In: Proceedings of the Institution of Mechanical Engineers, 220 (12): 1997-2020.

UK Regulators Network (2015). Innovation in regulated infrastructure sectors. Summary report.

Van Erp J. 2011. "Naming without shaming: the publication of sanctions in the Dutch financial market". Regulation and Governance, 5: 287-308.

Vigoda-Gadot, E., Shoham, A., Schwabsky, N and Ruvio, A. 2005. "Public sector innovation for the managerial and the post-managerial era: Promises and realities in a globalizing public administration." International Public Management Journal, 8 (1): 57-81

Walker, R.M. 2007." An empirical evaluation of innovation types and organizational and environmental characteristics: towards a configuration framework." Journal of Public Administration Research and Theory, 18: 591-615.

Walker, R.M. 2014. "Internal and External Antecedents of Process Innovation: a review and extension". Public Management Review, 16 (1): 21-44

Water Industry Commission Scotland (2013). Strategic review of charges 2015-2021: Innovation and Choice.

Yin, R.K. 2013. "Case Study Research: Design and Methods", $5^{\text {th }}$ ed, Sage Publications 


\begin{tabular}{|c|c|c|c|c|}
\hline \multirow{8}{*}{ 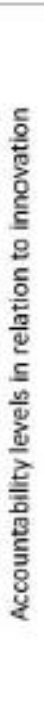 } & & \multicolumn{3}{|c|}{ Innovation in relation to regulatory regimes } \\
\hline & & $\begin{array}{l}\text { Prescriptive (rules and } \\
\text { compliance) }\end{array}$ & $\begin{array}{l}\text { System-based (process and } \\
\text { management) }\end{array}$ & $\begin{array}{l}\text { Performance-based (outcomes and } \\
\text { measures] }\end{array}$ \\
\hline & Legal & $\begin{array}{l}\text { Transkarency in setting } \\
\text { rules ant standards }\end{array}$ & $\begin{array}{l}\text { Transparency in establishing } \\
\text { features of desired systems }\end{array}$ & $\begin{array}{l}\text { Transparency in establishing } \\
\text { performance goals }\end{array}$ \\
\hline & Bureaucratic/ & $\begin{array}{l}\text { Accountability of } \\
\text { the Government }\end{array}$ & ornment & \\
\hline & administrative & $\begin{array}{l}\text { Monitoring for } \\
\text { adherence to prescribed } \\
\text { rules }\end{array}$ & $\begin{array}{l}\text { Wonitoring for the adequacy } \\
\text { of mangement system }\end{array}$ & $\begin{array}{l}\text { Monitoring for adherence to } \\
\text { performance goals }\end{array}$ \\
\hline & Professional & & $\begin{array}{l}\text { Professional expertise } \\
\text { of the stakeholders }\end{array}$ & \\
\hline & 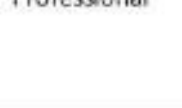 & $\begin{array}{l}\text { Enforcement decisions } \\
\text { by regulatory inspectors }\end{array}$ & $\begin{array}{l}\text { System design decisions by } \\
\text { regulated entities }\end{array}$ & $\begin{array}{l}\text { Adherence to performance goals by } \\
\text { rewlated entities }\end{array}$ \\
\hline & Political & $\begin{array}{l}\text { Triggered by complaints } \\
\text { about regulatory } \\
\text { process }\end{array}$ & $\begin{array}{l}\text { Triggered by multiple system } \\
\text { breakdowns }\end{array}$ & $\begin{array}{l}\text { Triggered by systerwatic undesired } \\
\text { outcomes }\end{array}$ \\
\hline
\end{tabular}

Figure 1: Mobility across regulatory regimes (adapted from May 2007)

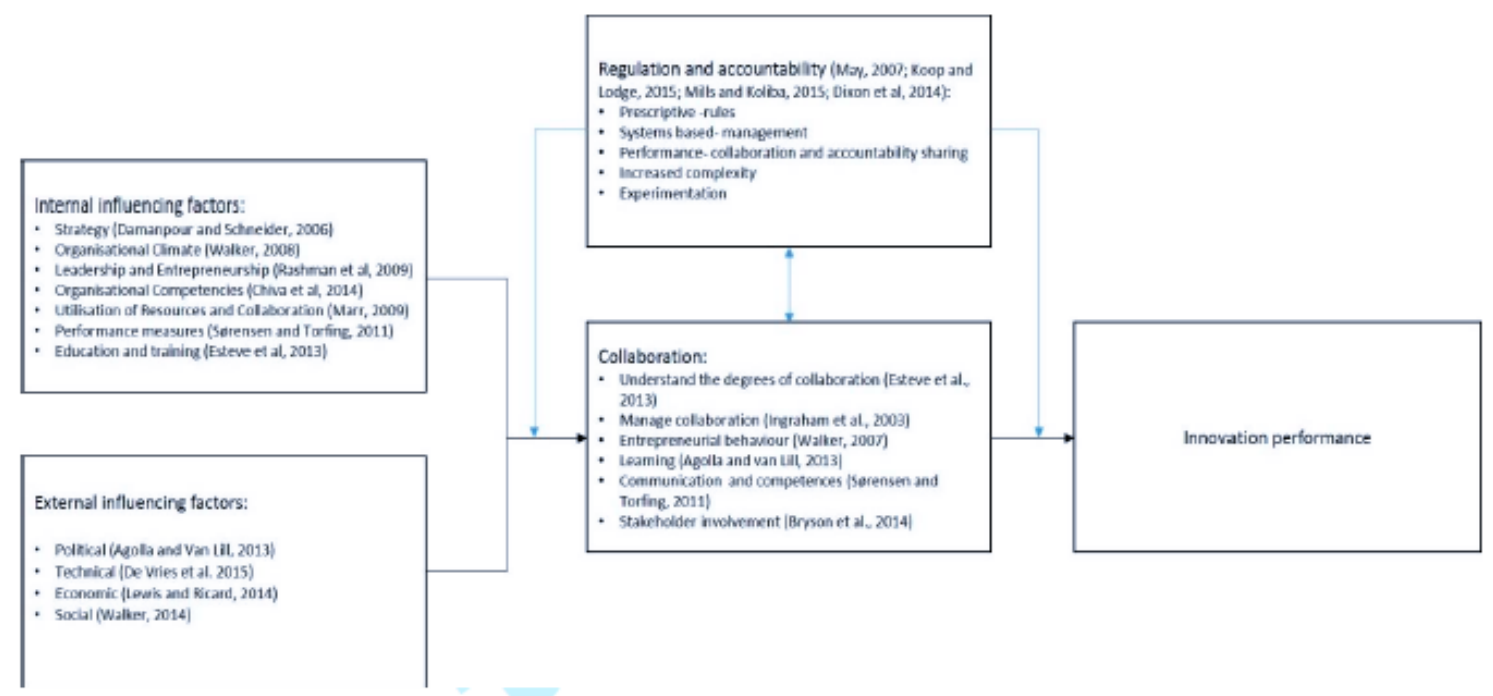

Figure 2: The role of regulatory regimes in public sector innovation 


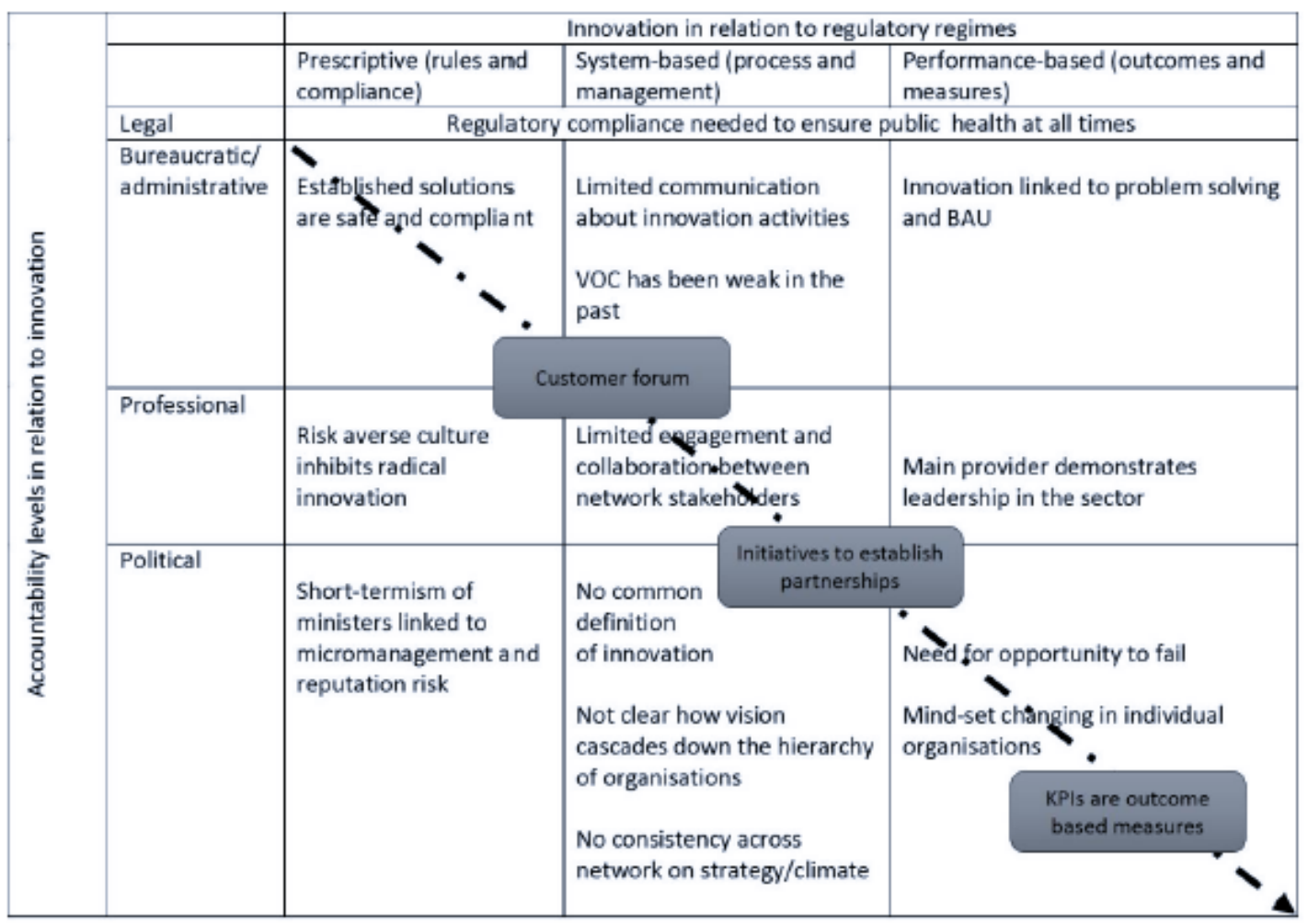

Figure 3: Innovation in relation to regulatory regimes 